\title{
Genetic techniques and circuit analysis
}

\section{William Wisden $^{1 *}$ and Jochen C. Meier ${ }^{2 * *}$}

\author{
1 Division of Cell and Molecular Biology, Imperial College London, London, UK \\ 2 Max Delbrück Center for Molecular Medicine, Berlin, Germany \\ Correspondence: *w.wisden@imperial.ac.uk; **jochen.meier@mdc-berlin.de
}

Reaching an understanding of how neuronal circuits work and what they compute is a fundamental aim of neuroscience, perhaps even the most fundamental. We have to both establish the connections between cell types and reversibly manipulate their activity cell-typeselectively. Such work sounds in principle straight-forward, but it has been difficult to achieve. This has now all changed. There has been a quite remarkable development of genetic techniques published in the last years, so that the topic of "Genetic techniques and circuit analysis" covered by the articles in this Special Issue is truly flourishing. The extremely easy applicability of the channelrhodopsin-2 system (ChR2) in diverse animals and circuit settings has been a phenomenal breakthrough and captured the imagination of the neuroscience community (see, for example, Adamantidis et al., 2009; Han et al., 2009). A major advantage of ChR2 is that precise patterns of activation can be delivered cell-type selectively, to probe, for example, the requirements for rhythm generation in a network. This has been termed "informational lesioning" (Han et al., 2009). Yet in spite of its undoubted importance and significance, ChR2 is just one of many possibilities that could be deployed. Indeed, one of the most enjoyable aspects of researching brain circuits is that so many methods and approaches exist. There is no "one size fits all" solution for the challenge of selecting particular genetic technique(s). In this collection of articles for the themed Special Issue, the broad nature of this area is apparent. The articles cover cell type-selective manipulations of neuronal activity using light (Alilain and Silver, 2009; Adamantidis et al., 2009; Han et al., 2009), unique ligand-receptor combinations (Nichols and Roth, 2009; Wisden et al., 2009), other manipulations of ion channels to control neuronal activity (Hodge, 2009; Holford et al., 2009; White and Peabody, 2009) or, in Drosophila, the deployment of reversible blockade of neurotransmission using the shibire ${ }^{\text {ts }}$ system or tetanus toxin (also in mice) (Kasuya et al., 2009; Tessier and Broadie, 2009; White and Peabody, 2009). Indeed, in Drosophila, the ease of applicability of genetic screens for behavioural phenotypes means that combined enhancer trapping and manipulation of neuronal activity is allowing advances in establishing what, or how, particular types of neurons contribute to behaviour, a process of discovery termed by White and Peabody as "neurotrapping". Reijmers and
Mayford (2009) provide an elegant extension of circuit mapping using genetic techniques; here, the TetTag mouse line permits exploration of how activity in small ensembles of neurons contributes to memory formation. Finally, while we are considerably far from any therapies based on the methods described in this Special Issue, ChR2 activation with light has succeeded in partially repairing breathing defects produced by spinal cord lesions in experimental animals (Alilain and Silver, 2009).

Although there is much emphasis on manipulating reversibly the activity of particular cell types in circuits, other techniques covered in this Special Issue remain vital. The 2008 Nobel Prize in Chemistry went to O. Shimomura, M. Chalfie and R.Y. Tsien for the discovery and development of green fluorescent protein (GFP). GFP and it variants (e.g. YFP) are now such "household" items in our molecular toolboxes that it is difficult to imagine doing any molecular biology research without them. In our Special Issue, Bregestovski et al. (2009) appraise YFP-based $\mathrm{Cl}^{-}$indicators for measuring $\mathrm{Cl}^{-}$concentrations; Perron et al. (2009) review voltagesensitive fluorescent proteins (VSFPs). All of these indicators can be used in specific cell types or cellular compartments to reveal the ionic milieu of in vivo circuitry. Another recent Nobel Prize (2007) in Physiology or Medicine went to M.R. Capecchi, M.J. Evans and O. Smithies for their development, using mouse embryonic stem cells, of a general method for manipulating the mouse genome. The technology has been so successful that knockouts are now high throughput; indeed, the Knockout Mouse Project (KOMP) plans to knockout every mouse gene, and make conditional alleles for many genes. Resources such as GENSAT will soon offer Cre driver mouse lines for region-selective and cell-type-selective knockouts. There is, however, a feeling among some that knockouts, because of compensations that emerge as a consequence of losing the protein, are not always worth making. In our view this is wrong. Loss of function gene mutations, whether spontaneous (i.e. classical genetics) or engineered, have given, and continue to give, essential information about the roles of a protein in the organism (see Heldt and Ressler, 2009; Tessier and Broadie, 2009; Weber et al., 2009; Wisden et al., 2009).

We warmly thank all the Contributors for their articles.

\section{REFERENCES}

Adamantidis, A., Carter, M. C., and de Lecea, L. (2009). Optogenetic deconstruction of sleep-wake circuitry in the brain. Front. Mol. Neurosci. 2:31. doi: 10.3389/neuro.02.031.2009.

Alilain, W. J., and Silver, J. (2009). Shedding light on restoring respiratory function after spinal cord injury. Front. Mol. Neurosci. 2:18. doi: 10.3389/neuro.02.018.2009.

Bregestovski, P., Waseem, T., and Mukhtarov, M. (2009). Genetically encoded optical sensors for monitoring of intracellular chloride and chloride-selective channel activity. Front. Mol. Neurosci. 2:15. doi: 10.3389/neuro.02.015.2009.
Han, X., Qian, X., Stern, P., Chuong, A., and Boyden, E. S. (2009). Informational lesions: optical perturbation of spike timing and neural synchrony via microbial opsin gene fusions. Front. Mol. Neurosci. 2:12. doi: 10.3389/neuro.02.012.2009.

Heldt, S. A., and Ressler, K. J. (2009). The use of lentiviral vectors and Cre/loxP to investigate the function of genes in complexbehaviors.Front.Mol.Neurosi. 2:22. doi: 10.3389/neuro.02.022.2009.

Hodge, J. (2009). Ion channels to inactivate neurons in Drosophila. Front. Mol. Neurosci. 2:13. doi: 10.3389/neuro.02.013.2009.

Holford, M., Auer, S., Laqua, M., and Ibañez-Tallon, I. (2009). 
Manipulating neuronal circuits with endogenous and recombinant cell-surface tethered modulators. Front. Mol. Neurosci. 2:21. doi: 10.3389/neuro.02.021.2009.

Kasuya, J., Ishimoto, H., and Kitamoto, T. (2009). Neuronal mechanisms of learning and memory revealed by spatial and temporal suppression of neurotransmission using shibirets1, a temperature-sensitive dynamin mutant gene in Drosophila melanogaster. Front. Mol. Neurosci. 2:11. doi: 10.3389/neuro.02.011.2009.

Nichols, C. D., and Roth, B. L. (2009). Engineered G-protein coupled receptors are powerful tools to investigate biological processes and behaviors. Front. Mol. Neurosci. 2:16. doi: 10.3389/neuro.02.016.2009.

Perron, A., Mutoh, H., Akemann, W., Ghimire Gautam, S., Dimitrov, D., Iwamoto, Y., and Knöpfel, T. (2009). Second and third generation voltage-sensitive fluorescent proteins for monitoring membrane potential. Front. Mol. Neurosci. 2:5. doi: 10.3389/neuro.02.005.2009.

Reijmers, L., and Mayford, M. (2009). Genetic control of active neural circuits. Front. Mol. Neurosci. 2:27. doi: 10.3389/neuro.02.027.2009.

Tessier, C. R., and Broadie, K. (2009). Activity-dependent modulation of neural circuit synaptic connectivity. Front. Mol. Neurosci. 2:8. doi: 10.3389/neuro.02.008.2009.

Weber, T., Böhm, G., Herrmann, E. Schütz, G., Schönig, K., and Bartsch, D. (2009). Inducible gene manipulations in serotonergic neurons. Front. Mol. Neurosci. 2:24. doi: 10.3389/neuro.02.024.2009.

White, B. H., and Peabody, N. C. (2009). Neurotrapping: cellular screens to identify the neural substrates of behavior in Drosophila. Front. Mol. Neurosci. 2:20. doi 10.3389/neuro.02.020.2009.

Wisden, W., Murray, A. J., McClure, C. J., and Wulff, P. (2009). Studying cer- ebellar circuits by remote control of selected neuronal types with GABA receptors. Front. Mol. Neurosci. 2:29. doi: 10.3389/neuro.02.029.2009.

Received: 19 January 2010; published online: 03 March 2010.

Citation: Front. Mol. Neurosci. (2010) 3:4. doi: 10.3389/neuro.02.004.2010

Copyright (c) 2010 Wisden and Meier. This is an open-access article subject to an exclusive license agreement between the authors and the Frontiers Research Foundation, which permits unrestricted use, distribution, and reproduction in any medium, provided the original authors and source are credited. 